\title{
Reply to Sauther and Cuozzo 2012
}

\author{
Jens Lorenz Franzen • Jörg Habersetzer • \\ Evelyn Schlosser-Sturm • Erik Lorenz Franzen
}

Received: 12 February 2013 / Accepted: 2 April 2013 / Published online: 15 May 2013

(C) Senckenberg Gesellschaft für Naturforschung and Springer-Verlag Berlin Heidelberg 2013

Referring to long-term studies of living lemurs, Sauther and Cuozzo (2012) advanced doubts concerning our interpretation of a serious injury and its consequences for "Ida" (Darwinius masillae) - the famous fossil primate from the early middle Eocene of Grube Messel (Germany) (Franzen et al. 2011, 2012). We appreciate the intense efforts and the immense value of field studies for the interpretation of the palaeobiology of fossils, but we have objections concerning the comparisons and conclusions of Sauther and Cuozzo (2012).

1. From Sauther and Cuozzo's presentations it is not clear whether the injuries they observed in living lemurs were really as serious as the trauma "Ida" was suffering. It is the question as to whether Sauther and Cuozzo's Lemur catta (Lemur \# 115) was seriously injured at all. Sauther and Cuozzo's remark (2012: 580) "the wrist was swollen with the carpal bones calcified to the point that crepitus was evident when the wrist was moved" does not point to an injury comparable to that of "Ida". Also, the abscess of that Lemur (Sauther and Cuozzo 2012: 582, fig. 8a) looks rather harmless.

2. The "dramatic injuries" that Sauther and Cuozzo mentioned and figured of other individuals (2012: 580-581, fig. 7) are rather simple fractures that were observed after healing. They show nothing of a crippling or a seriously injured articulation, and they do not refer to a

J. L. Franzen $(\bowtie) \cdot$ J. Habersetzer $\cdot$ E. Schlosser-Sturm Senckenberg Forschungsinstitut und Naturmuseum Frankfurt a. M., Senckenberganlage 25, 60325 Frankfurt am Main, Germany e-mail: jfranzen@senckenberg.de

\section{J. L. Franzen}

Naturhistorisches Museum Basel, Augustinergasse 2, 4001 Basel, Switzerland

\section{E. L. Franzen}

Marien-Hospital Witten, Marienplatz 2,

58452 Witten, Germany juvenile individual such as "Ida" (Darwinius masillae), who was a very young female only 10 months old (Smith in Franzen et al. 2009).

3. We did not claim that "Ida's" injury was "a direct factor in her death" (Sauther and Cuozzo 2012: 581). On the contrary, "Ida's" crippled hand led to exposing her to poisonous gases. In our opinion, these gases and not her fall or injury caused "Ida's" death.

Summarising, Sauther and Cuozzo's observations of the climbing capabilities of injured living lemurs are limited, because the individuals were only occasionally observed, and radiographs proving the alleged seriousness of their injuries are missing. Therefore, applying Sauther and Cuozzo's data to "Ida's" case appears for us not to be useful. Also, contrary to our hypothesis, Sauther and Cuozzo's explanation of "Ida's" death as due to an infected abscess would not explain how her body got into Eocene Lake Messel.

\section{References}

Franzen JL, Gingerich PD, Habersetzer J, Hurum JH, Koenigswald W, Smith H (2009) Complete Primate Skeleton from the Middle Eocene of Messel in Germany: Morphology and Paleobiology. PLoS ONE 4(5):1-27. doi:10.1371/journal.pone.0005723, e5723

Franzen JL, Habersetzer J, Schlosser-Sturm E, Franzen EL (2011) Paleopathology of Darwinius masillae (Mammalia, Primates). In: Lehmann T, Schaal SFK (eds) The world at the time of Messel: puzzles in the palaeobiology, palaeoenvironment, and the history of the early primates (22nd Int Senckenberg Conf, conference volume). Senckenberg Gesellschaft für Naturforschung, Frankfurt am Main, pp 61-62

Franzen JL, Habersetzer J, Schlosser-Sturm E, Franzen EL (2012) Palaeopathology and fate of Ida (Darwinius masillae, Primates, Mammalia). Palaeobio Palaeoenv 92(4):567-572. doi:10.1007/ s12549-012-0102-8

Sauther ML, Cuozzo FP (2012) Understanding Eocene primate palaeobiology using a comprehensive analysis of living primate ecology, biology and behaviour. Palaeobio Palaeoenv 92(4):573583. doi:10.1007/s12549-012-0089-1 